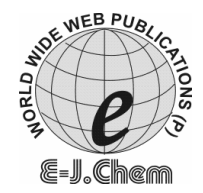

http://www.e-journals.net
ISSN: 0973-4945; CODEN ECJHAO

E-Journal of Chemistry 2010, 7(2), 569-577

\title{
A Simple and Validated Reverse Phase HPLC Method for the Determination of Rabeprazole in Pharmaceutical Dosage Forms
}

\author{
UMA MAHESH KARRA* and SANJEEVA YARKALA \\ Analytical Research and Development Laboratory, \\ International Specialty Products India Pvt.Ltd., \\ No. 6-3-1090/A, Somajiguda, Hydrabad-500 082, India. \\ maheshkmpharm@gmail.com
}

Received 9 August 2009; Accepted 5 October 2009

\begin{abstract}
A simple and rapid reverse phase high performance liquid chromatography (RP-HPLC) method was developed and validated for quantitative determination of rabeprazole in bulk drug samples and formulations. Rabeprazole was analyzed by using reverse phase LC-GC column (Inertsil ODS, $4.6 \mathrm{~mm} \times 25 \mathrm{~cm}, 5$ microns), with mobile phase consisting of methanol: water $(78: 22 \mathrm{v} / \mathrm{v})$. The flow rate was set $1.0 \mathrm{~mL} / \mathrm{min}$ and analysis was performed at wavelength $288 \mathrm{~nm}$ using Photo Diode Array (PDA) detector at ambient temperature. The method was validated and stability studies were conducted under different conditions. The retention time for rabeprazole was around 4.12 minutes. The calibration curves were linear $(r \geq 0.9998)$ over a concentration range from 20.0 to $80.0 \mu \mathrm{g} / \mathrm{mL}$. Limit of detection (LOD) and Limit of quantitation (LOQ) were $8 \mathrm{ng} / \mathrm{mL}$ and $24 \mathrm{ng} / \mathrm{mL}$ respectively. The developed method was successfully applied to estimate the amount of rabeprazole in tablet formulations.
\end{abstract}

Keywords: RP-HPLC, PDA, Rabeprazole, Pharmaceutical dosage forms.

\section{Introduction}

Rabeprazole is a substituted benzimidazole that inhibits gastric acid secretion and primarily used in the treatment of Ulcerative Gastroesophageal Reflux Disease (GERD). It is chemically 2-[[[4-(3-methoxy propoxy)-3-methyl-2-pyridinyl] sulfinyl]- $H$-benimidazole (Figure 1). Rabeprazole is officially used as $\mathrm{PDR}^{1}$. Rabeprazole belongs to a class of antisecretary compounds that suppress gastric acid secretion by inhibiting the gastric $\mathrm{H}^{+}$, $\mathrm{K}^{+}$ATPase at the secretary surface of the gastric parietal cell. Because this enzyme is regarded as the acid (proton) pump within the parietal cell, rabeprazole has been characterized as a gastric proton pump inhibitor. Rabeprazole blocks the final step of gastric secretion. In gastric parietal cells, rabeprazole is protonated, accumulates and is transformed to an active sulfonamide ${ }^{2}$. 


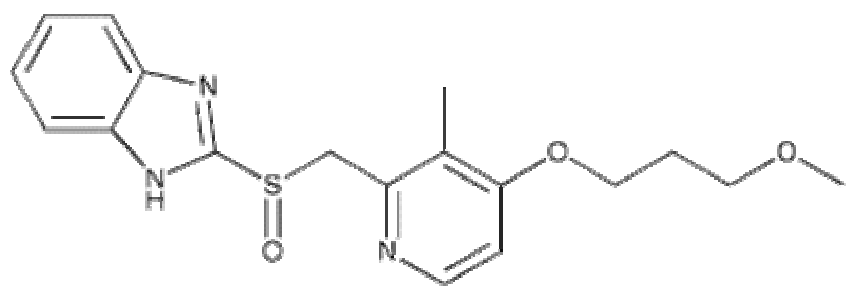

Figure 1. Chemical structure of rabeprazole

Few HPLC methods for quantitative determination of rabeprazole were reported in literature. Majority of these HPLC methods were applied in the determination of rabeprazole and its metabolites using buffer solutions and biological fluids ${ }^{3-8}$ and are mainly useful for therapeutic monitoring of rabeprazole. No validated HPLC methods for quantitative determination of rabeprazole in bulk drug samples and formulations were reported till date with chromatographic method discussed in this study. In order to minimize batch-to-batch variation there is an immense need for developing a rapid, sensitive and validated analytical method for day-to-day analysis of the drug in pharmaceutical dosage forms.

\section{Experimental}

Rabeprazole bulk drug was purchsed from MetroChem API Pvt Ltd, Hyderabad, India. Rabeprazole formulations (Tablets) were procured from ISP (International Specialty Products), India Branch office-Hyderabad. Methanol (HPLC grade) was obtained from Merck, Mumbai. HPLC grade deionised water (Nanopure Diamond Barnstead Thermolyne, USA) was used throughout the analysis.

\section{Instrumentation}

The HPLC system consisted of Waters Alliance (Waters Corporation, MA, USA) equipped with a Waters 2695 solvent delivery module in a quaternary gradient mode and a Waters 2669 PDA detector. Data acquisition was performed by the Empower $2^{\circledR}$ software operated on a Pentium ${ }^{\circledR}$ IV microprocessor. Analysis was carried out at $288 \mathrm{~nm}$ with reversed phase GL Sciences column, (Inertsil ODS, $250 \times 4.6 \mathrm{~mm}, 5 \mu \mathrm{m}$ ) at ambient temperature. The mobile phase consisted of Methanol: Water $(78: 22 \mathrm{v} / \mathrm{v})$ set at a flow rate of $1.0 \mathrm{~mL} / \mathrm{min}$. The mobile phase was degassed and filtered through $0.45 \mu \mathrm{m}$ membrane filter before pumping into HPLC system.

\section{Preparation of solutions}

\section{Preparation of rabeprazole stock solution}

The stock solution was prepared by dissolving accurately weighed quantity of $10 \mathrm{mg}$ of the drug in $10 \mathrm{~mL}$ of deionised mobile phase (final concentration, $1 \mathrm{mg} / \mathrm{mL}$ ). From stock solution, standard solution containing $100 \mu \mathrm{g} / \mathrm{mL}$ rabeprazole was prepared by suitably diluting the appropriate volume of stock solution with mobile phase.

\section{Calibration standards and quality control samples}

Different calibration standards ranging from $20,30,40,60$ and $80 \mu \mathrm{g} / \mathrm{mL}$ were prepared by appropriate dilution of standard solution $(100 \mu \mathrm{g} / \mathrm{mL})$ with mobile phase. Three quality control samples at concentrations 28,40 and $52 \mu \mathrm{g} / \mathrm{mL}$ representing 70,100 and $130 \%$ respectively of assay concentration $(40 \mu \mathrm{g} / \mathrm{mL})$ were prepared from the standard solution. An aliquot of $20 \mu \mathrm{L}$ of solution was injected into HPLC system. 


\section{Preparation of assay solution}

An accurately weighed, $20 \mathrm{mg}$ of rabeprazole, was transferred to a $50 \mathrm{~mL}$ volumetric flask, diluted with mobile phase to volume and mixed. A volume of $5.0 \mathrm{~mL}$ of this solution was pipetted to another $50 \mathrm{~mL}$ volumetric flask, diluted to volume with mobile phase and mixed (final Concentration of $0.04 \mathrm{mg} / \mathrm{mL}$ ) and $20 \mu \mathrm{L}$ of this solution was injected into the HPLC system.

\section{Method validation}

\section{System suitability}

The system suitability was assessed by replicate analysis of six injections of the drug at a concentration of $40 \mu \mathrm{g} / \mathrm{mL}$. The acceptance criterion was $\pm 2 \%$ for the percent coefficient of variation $(\% \mathrm{CV})$ for the peak area and retention times for rabeprazole. The number of theoretical plates should be $>2500$ and the tailing factor should be $<2.0$.

\section{Determination of limit of detection (LOD) \& limit of quantitation (LOQ)}

A series of dilute solutions were prepared in the range of $0.2 \%, 0.5 \%$ and $1.0 \%$ of the assay concentration $(40 \mu \mathrm{g} / \mathrm{mL})$ using the standard solutions. Equal volumes $(20 \mu \mathrm{L})$ of each of the above solutions were injected in 5 times and the areas were calculated due to Rabeprazole peak. The standard deviation for the 5 injections for each concentration was calculated. Based on the data obtained, the standard deviation at concentration 0 was calculated and this value was used for the calculation of the LOD and LOQ using the formulae:

$$
\mathrm{LOD}=(3.3 \sigma / \mathrm{S}) \text { and } \mathrm{LOQ}=(10 \sigma / \mathrm{S})
$$

Where, $\sigma$ - standard deviation and $S$ is slope of regression line $e^{9,10}$.

\section{Linearity (Calibration curve)}

Calibration curve was constructed with 5 concentrations ranging from 20 to $80 \mu \mathrm{g} / \mathrm{mL}$. The peak area ratio of the drug was considered for plotting the linearity graph. The linearity was evaluated by linear regression analysis, which was calculated by the least square regression method.

\section{Accuracy and precision}

Accuracy was carried out by recovery experiments. Quality control sample solutions of 70, 100 and $130 \%$ (of $40 \mu \mathrm{g} / \mathrm{mL}$ ) containing the excipients used in the formulations were tested and the recovery was calculated in each case using the regression line equation developed under the linearity experiment. Demonstration of precision was done under two categories. The injection reproducibility was assessed by using 6 injections of the standard solution for rabeprazole and the relative standard deviation of the replicate injection was calculated. In addition, to demonstrate method precision, 5 samples from the same batch of formulation were analyzed individually and the assay content of each sample was estimated. Average of 5 determinations was calculated along with RSD for the replicate determinations.

\section{Specificity and stability}

Specificity was demonstrated through forced degradation studies conducted on the sample using acid, alkaline, oxidative, reductive and photolytic degradations. Sample was exposed to these conditions and the main peak was studied for peak purity, thus indicating that the method effectively separated the degradation products from the rabeprazole active ingredient. 


\section{Acid degradation}

Rabeprazole $20.0 \mathrm{mg}$ pure drug was accurately weighed and transferred to a $50 \mathrm{~mL}$ volumetric flask. About $1 \mathrm{~mL}$ of $1 \mathrm{~N}$ HCL was added. The volumetric flask was placed on water bath maintained at $60{ }^{\circ} \mathrm{C}$ for one hour. Then it was cooled, dissolved and volume was made with mobile phase.

\section{Alkaline degradation}

Rabeprazole $20.0 \mathrm{mg}$ pure drug was accurately weighed and transferred to a $50 \mathrm{~mL}$ volumetric flask. $1 \mathrm{~mL}$ of $1 \mathrm{~N} \mathrm{NaOH}$ was added. The volumetric flask was placed on a water bath maintained at $60{ }^{\circ} \mathrm{C}$ for one hour. Then it was cooled, dissolved and volume was made with mobile phase.

\section{Reductive degradation}

Rabeprazole $20.0 \mathrm{mg}$ pure drug was accurately weighed and transferred to a $50 \mathrm{~mL}$ volumetric flask. zinc and $1 \mathrm{~mL}$ of $1 \mathrm{~N} \mathrm{HCL}$ were added. The volumetric flask was placed on a water bath maintained at $60{ }^{\circ} \mathrm{C}$ for one hour. Then it was cooled, dissolved and volume was made with mobile phase.

\section{Oxidative degradation}

Rabeprazole $20.0 \mathrm{mg}$ pure drug was accurately weighed and transferred to a $50 \mathrm{~mL}$ volumetric flask. $1 \mathrm{~mL}$ of $\mathrm{H}_{2} \mathrm{O}_{2}(1 / 20)$ was added, dissolved and volume was made with mobile phase.

\section{Photolytic degradation}

Rabeprazole $20.0 \mathrm{mg}$ pure drug was accurately weighed and transferred to a $50 \mathrm{~mL}$ volumetric flask, dissolved and volume was made with mobile phase. The solution was exposed to UV light at $300 \mathrm{~nm}$ for 8 hours. In all the forced degradation studies, a volume of $5.0 \mathrm{~mL}$ of each of the solutions from the degradation experiments, were transferred to a $50 \mathrm{~mL}$ volumetric flask. The volume was made with mobile phase and mixed so as to get a final concentration of $40 \mu \mathrm{g} / \mathrm{mL}$. Standard solution with final concentration of $40 \mu \mathrm{g} / \mathrm{mL}$ was prepared. And equal volumes of all the above 6 solutions $20 \mu \mathrm{L}$ ) were injected into the chromatograph and the chromatograms were recorded.

\section{Stability}

The solution stability was demonstrated by conducting repeated autosampler analysis of the standard solution at periodic intervals covering a time period of 24 hours. The areas for each of the experiment were taken and subjected to statistical analysis.

\section{Robustness and ruggedness}

The robustness/ruggedness of the method was demonstrated through the study of the following variations.

1. Column to Column Variation

2. Day to Day Variation

3. Analyst to Analyst Variation

These parameters were studied through a matrix design involving the estimation on two different days using two different columns and 2 different analysts with a total of 4 determinations. Under each conditions, samples were analyzed including a duplicate injection for each estimate. 


\section{Results and Discussion}

\section{Method development and optimization}

Rabeprazole is soluble in water. It can be separated by Inertsil ODS column $(250 \times 4.6 \mathrm{~mm}, 5 \mu \mathrm{m})$ with excellent reproducibility. For the present RP-HPLC method, chromatographic conditions were optimized to achieve the best resolution and peak shape. Different mobile phases containing methanol and water were examined and the composition containing $78 \%$ methanol and $22 \%$ water was selected as optimal for obtaining well-resolved peaks with acceptable system suitability parameters (theoretical plates, resolution factor and asymmetry). The optimum wavelength for detection and quantization was $288 \mathrm{~nm}$, at which the best detector response was obtained for rabeprazole API and in formulations.

\section{Method validation}

\section{System suitability}

The $\% \mathrm{CV}$ of peak area and retention time for the drug were within $2 \%$ indicating the suitability of the system (Table 1). The efficiency of the column was expressed by number of theoretical plates for the 6 replicate injections was $2940.15 \pm 0.025 \%$ (mean $+\% \mathrm{CV}$ )and the USP tailing factor was $1.17 \pm 0.005 \%$ (mean $+\% \mathrm{CV}$ ).

Table 1. System suitability study of rabeprazole.

\begin{tabular}{ccccc}
\hline Injection & $\begin{array}{c}\text { Retention } \\
\text { time, min }\end{array}$ & Peak area & Plate count & $\begin{array}{c}\text { Tailing } \\
\text { factor }\end{array}$ \\
\hline 1 & 4.120 & 1577598 & 2938.69 & 1.17 \\
2 & 4.119 & 1577312 & 2818.89 & 1.17 \\
3 & 4.116 & 1577867 & 3038.06 & 1.17 \\
4 & 4.115 & 1576892 & 2958.57 & 1.17 \\
5 & 4.114 & 1577533 & 2898.51 & 1.16 \\
6 & 4.114 & 1576139 & 2988.15 & 1.18 \\
Mean & 4.116 & 1577223.5 & 2940.15 & 1.17 \\
S.D & 0.003 & 623.5 & 75.72 & 0.01 \\
$\%$ RSD & 0.001 & 0.0004 & 0.026 & 0.01 \\
\hline
\end{tabular}

\section{$L O D \& L O Q$}

The results indicated that the method was sensitive enough to detect a concentration of $8 \mathrm{ng} / \mathrm{m} \mathrm{L}$ and able to quantify at a concentration of above $24 \mathrm{ng} / \mathrm{mL}$.

\section{Linearity}

Calibration curve constructed was evaluated by its correlation coefficient. The peak area of the drug was linear in the range of 20.0 to $80.0 \mu \mathrm{g} / \mathrm{mL}$. The average areas for each of the concentration obtained were plotted against the concentration of the analyte. The correlation coefficient for the data was calculated as 0.9999 for rabeprazole indicating a strong correlation between concentration and area under curve.

A linear regression graph was drawn between the Concentration of the analyte and the areas. The regression line was observed to be $\mathrm{y}=1 \mathrm{E}+08 \mathrm{x}-277454$ for rabeprazole. Regression analysis was done at confidence level of $0.05(5 \%)$ and the data presented. The data indicated that the difference between the estimated area and the actual area was not 
significant. These experiments indicated that there was a linear relation between the amount of analyte and the areas were within the range studied (50\% to 200\%). The rabeprazole chromatogram extracted from the formulation and pure rabeprazole spiked in the mobile phase can be observed in Figure 2.

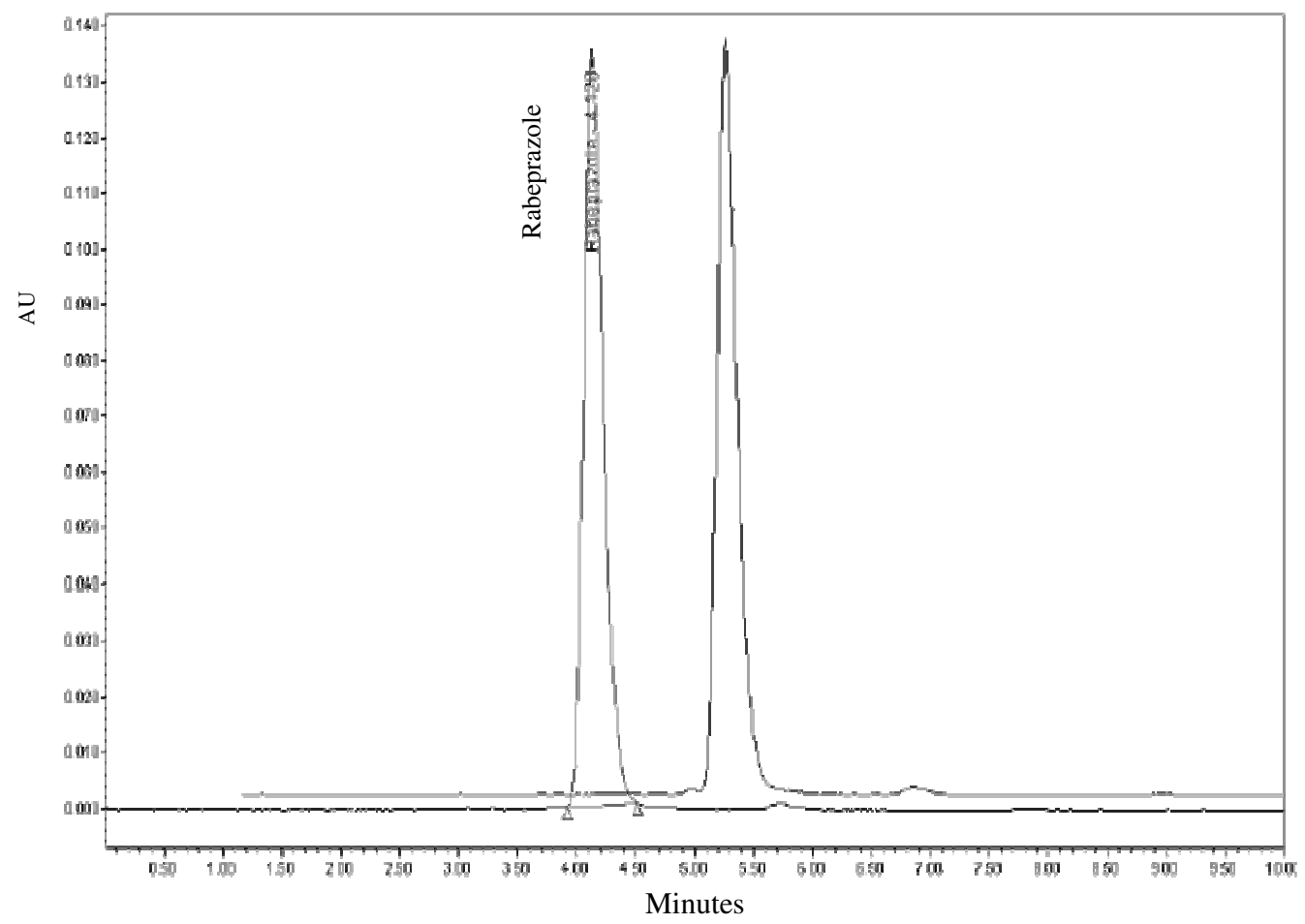

Figure 2. Chromatograms of rabeprazole (left to right) extracted from formulation (40 $\mu \mathrm{g} / \mathrm{mL})$ and standard solution $(40 \mu \mathrm{g} / \mathrm{mL})$

\section{Accuracy and precision}

Drug standard solutions of 70,100 and $130 \%$ containing the excipients used in the formulations were tested and the recovery was calculated in each of the case using the regression line equation developed under the Linearity experiment. A regression line Graph was drawn using the amount added on the $x$-axis and the amount found on the $y$-axis. The slope and intercept were calculated for the regression line (Method of Least Squares), and hypothesis was tested for the correlation between the amount added and amount found, at confidence level of 0.05 (5\%), using the t-statistic. The results revealed that there was a strong correlation between the amount added and amount found (Table 2). The results obtained from precision experiments also indicated a good method precision (Table 3).

\section{Specificity and stability}

The specificity was demonstrated through forced degradation studies conducted on the sample using acid, alkaline, oxidative, reductive and photolytic degradations (Table 4). Under each condition, the chromatogram was studied using PDA detector. Using the chromatographic software, the purity angle and purity threshold were calculated. 
Table 2. Accuracy results of recovery experiments.

\begin{tabular}{cccc}
\hline Spike level \% & $\begin{array}{c}\text { Amount } \\
\text { added }\end{array}$ & $\begin{array}{c}\text { Amount } \\
\text { found }\end{array}$ & \% Recovery \\
\hline 70 & 0.028 & 0.02802 & 100.06 \\
70 & 0.028 & 0.02800 & 100.00 \\
70 & 0.028 & 0.02800 & 100.00 \\
100 & 0.040 & 0.04002 & 100.05 \\
100 & 0.040 & 0.04003 & 100.08 \\
100 & 0.040 & 0.03997 & 99.93 \\
130 & 0.052 & 0.05200 & 100.00 \\
130 & 0.052 & 0.05259 & 101.14 \\
130 & 0.052 & 0.05256 & 101.08 \\
\multicolumn{4}{c}{ Mean } \\
\% RSD & 100.26 \\
\end{tabular}

Table 3. Precision.

\begin{tabular}{cccccc}
\hline Precision & \multicolumn{2}{c}{$\begin{array}{c}\text { Injection } \\
\text { reproducibility }\end{array}$} & \multicolumn{3}{c}{ Method precision } \\
\hline & Limit & RSD & Limit & Average & RSD \\
Rabeprazole & $2.00 \%$ & $0.21 \%$ & $98-102 \%$ & $101.08 \%$ & $0.13 \%$ \\
\hline
\end{tabular}

Table 4. Specificity data.

\begin{tabular}{clcc}
\hline S.No & \multicolumn{1}{c}{ Sample Name } & Purity 1Angle & $\begin{array}{c}\text { Purity 1 } \\
\text { Threshold }\end{array}$ \\
\hline 1 & Reductive degradation & 0.490 & 0.437 \\
2 & Acid degradation & 1.774 & 0.537 \\
3 & Photo Degradation & 10.952 & 0.291 \\
4 & Oxidation Degradation & 0.146 & 0.371 \\
5 & Alkaline Degradation & 0.140 & 0.296 \\
6 & Rabeprazole 100\% Solution & 10.372 & 0.285 \\
\hline
\end{tabular}

There was peak at the retention time of rabeprazole in acidic, alkaline and oxidative degradations, while there was some degradation of the rabeprazole under reductive and photolytic conditions. The rabeprazole peak was tested for the peak purity using the chromatographic software. The purity threshold and purity angle were estimated using the software and compared. In each case, it was observed that the purity threshold and purity angle values were varying with standard rabeprazole values indicating that the peak observed was pure except in cases of reductive and phtolytic degradations. However, the degradation products in these two conditions did not interfere with the rabeprazole peak indicating that the method was specific for the estimation of rabeprazole in the product under examination (Figure 3).Stability studies indicated that the samples were stable when kept at bench top for 12 hours (short-term), in auto-sampler for 24 hours. The results of these stability studies were given in Table 5, where the percent change was within the acceptance range of $99-101 \%$. 


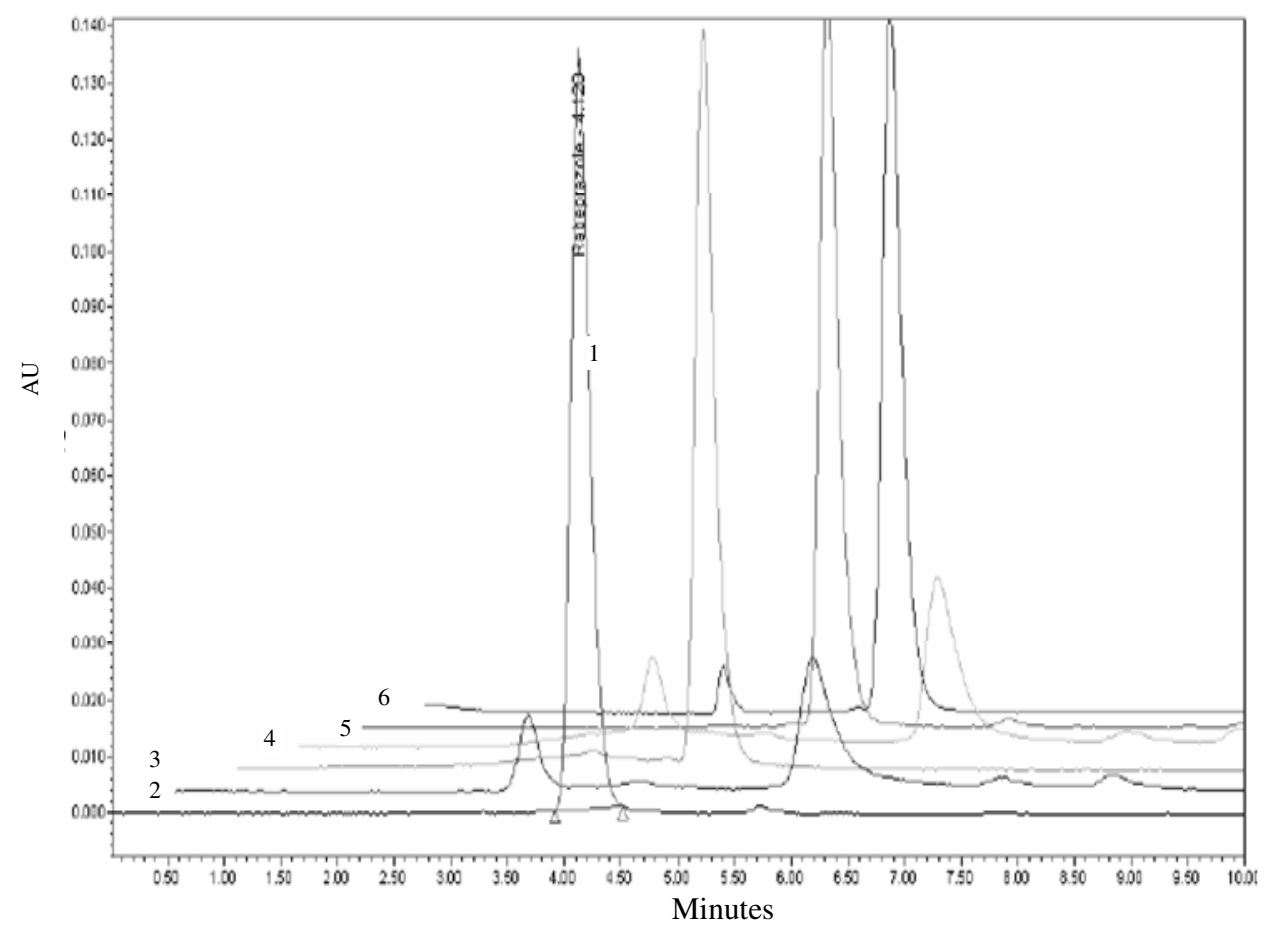

Figure 3. Chromatograms depicting the specificity of rabeprazole $(40 \mu \mathrm{g} / \mathrm{mL})$

1 Rabeprazole standard solution

2 Rabeprazole acid degradation

3 Rabeprazole alkaline degradation

$4 \quad$ Rabeprazole reductive degradation

5 --Rabeprazole photo degradation

6 ----Rabeprazole oxidation degradation

Table 5. Stability data.

\begin{tabular}{ccc}
\hline Description & Area & \% Change \\
\hline Initial & 1576757 & 100.00 \\
After 6 hours & 1588857 & 100.98 \\
After 12 hours & 1579855 & 100.20 \\
After 24 hours & 1575225 & 99.90 \\
Mean & 100.29 \\
\multicolumn{2}{c}{ Standard deviation } & 0.0044 \\
\% RSD & 0.43 \\
\hline
\end{tabular}

\section{Robustness and ruggedness}

The three parameters Column, Day and Analyst were studied through a matrix design involving the estimation on two different days using two different columns with a total of 4 determinations. Under each of the conditions, samples were analyzed including a duplicate injection for each estimate and the assay content of the analyte was estimated. It can be observed from the results that the values are well within acceptance limits of 98-102\%, with a $\mathrm{RSD}<2.0 \%$. Above experiments indicated that the method is rugged and provides consistent and reliable results. 


\section{Application of the method to dosage forms}

The HPLC method developed is sensitive and specific for the quantitative determination of rabeprazole. Also the method is validated for different parameters, hence has been applied for the estimation of drug in pharmaceutical dosage forms. Rabeprazole formulations (Tablets) were procured from ISP (International Specialty Products), India Branch officeHyderabad, were evaluated for the amount of rabeprazole present in the formulation. Each sample was analyzed in triplicate and the amount was $101.08 \%$. None of the injection excipients interfered with the analyte peak as seen in the Figure.2.

\section{Conclusion}

A rapid, specific isocratic HPLC method has been developed for the determination of Rabeprazole using a PDA detector. The method was validated for accuracy, precision, linearity, specificity \& stability, LOD \& LOQ and robustness \& ruggedness. The method uses a simple mobile phase composition, easy to prepare with little or no variation. The rapid run time of $10 \mathrm{~min}$ and the relatively low flow rate allows the analysis of large number of samples with less mobile phase that proves to be cost-effective. Efficient UV detection at $288 \mathrm{~nm}$ was found to be suitable without any interference from excipients or solvents. The calibration curves were linear $(r \geq 0.9998)$ over a concentration range from 20.0 to $80.0 \mu \mathrm{g} / \mathrm{mL}$. The relative standard deviations were $<1 \%$ and average recovery was $100.2 \%$. LOD and LOQ were $8 \mathrm{ng} / \mathrm{mL}$ and $24 \mathrm{ng} / \mathrm{mL}$ respectively. Stability experiments indicated that the solutions prepared were stable for a period of 24 hours and the results obtained in this period were reliable. The proposed HPLC method is fast, precise, accurate, sensitive, and efficient and can be used in routine analysis in quality control laboratories.

\section{References}

1. $\quad$ Physicians Desk Reference ${ }^{\circledR}$, PDR $^{\circledR} ; 57^{\text {th }}$ Edition, 2003, 312, 319, $1241,1771$.

2. Budavari S, Eds, Merck Index, $13^{\text {th }}$ Edition, 2001, 8181, Merck Research Lab.

3. Tsukasa Uno, Norio Yasui-Furukori, Mikiko Shimizu, Kazunobu Sugawara and Tomonori Tateishi, J Chromatogr B, 2005, 824(1-2), 238-243.

4. Nicole G M Hunfeld, Richard, van Rossen, William P GeUS and Daniel J Tou W, EJHP Science, 2008, 14(1), 8-13.

5. $\quad$ Prasanna Reddy Batter and Reddy M S, Asian J Res Chem., 2009, 2(1), 49-51

6. Reguri Buchireddy, Khagga Mukkanti, Polisetty Srinivasulu, Koduri S and Srinivas V, Chromatographia, 2009, 69(3-4), 381-384.

7. $\quad$ Radi A, Abd N, EL-Ghany and Wahdan T, Il Farmaco, 2004, 59(7), 515-518.

8. Pillai S and Singhvi I, Indian J Pharm Sci., 2008, 70, 658-561.

9. Validation of Analytical Methods: Definitions and Terminology, ICH Harmonised Tripartite Guideline, ICH Topic Q2A, 1994.

10. Validation of Analytical Procedures,Methodology, Step 4, Consensus, ICH Harmonised Tripartite Guideline, Guideline, 1996. 


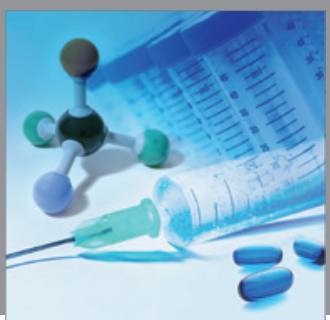

International Journal of

Medicinal Chemistry

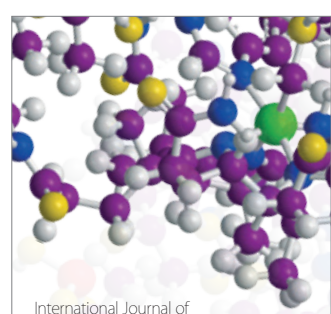

Carbohydrate Chemistry

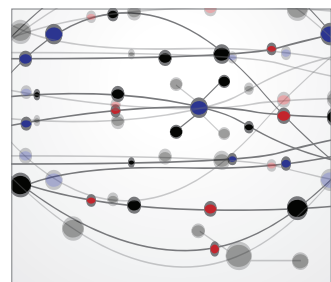

The Scientific World Journal
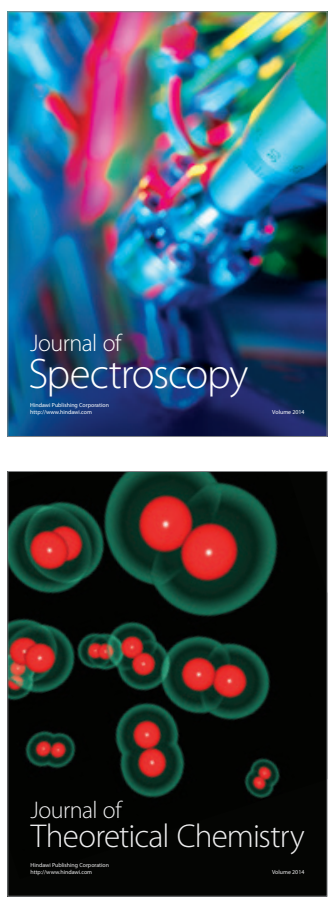
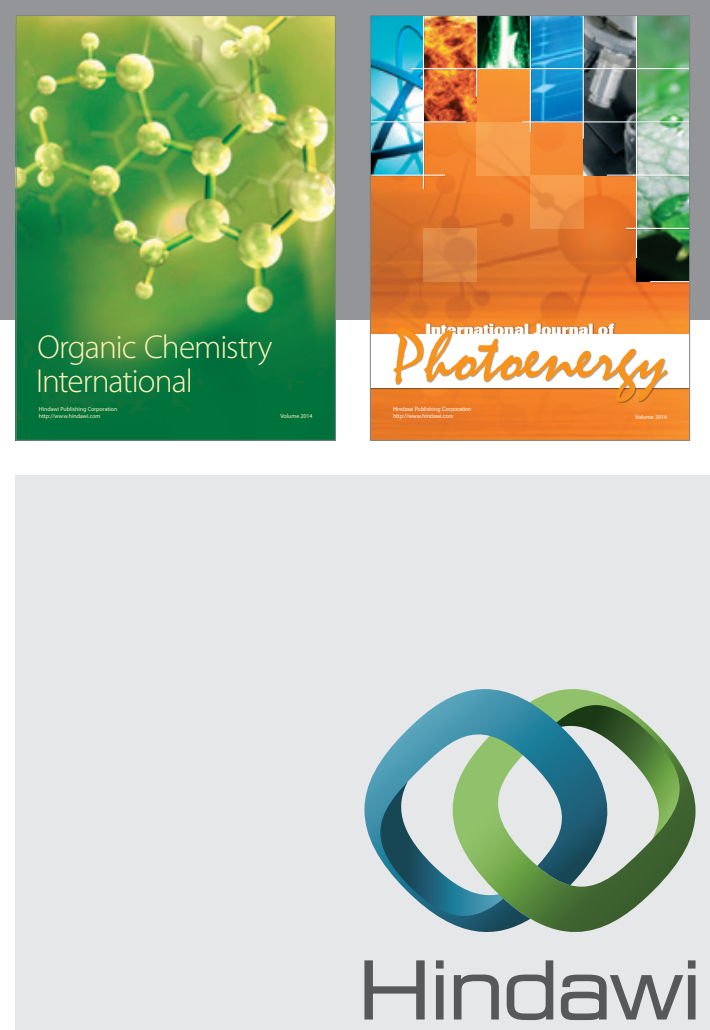

Submit your manuscripts at

http://www.hindawi.com
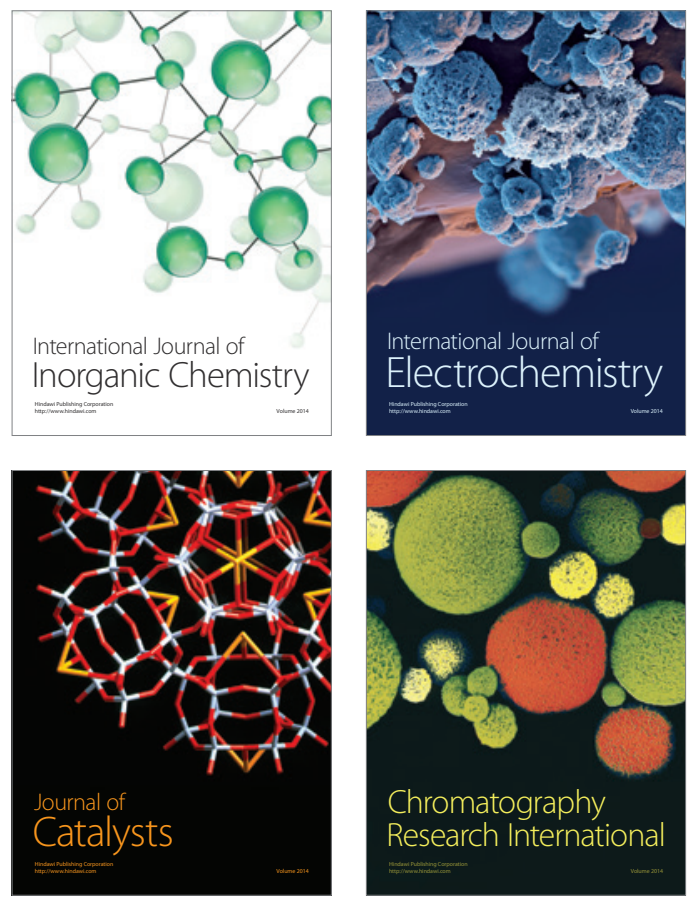
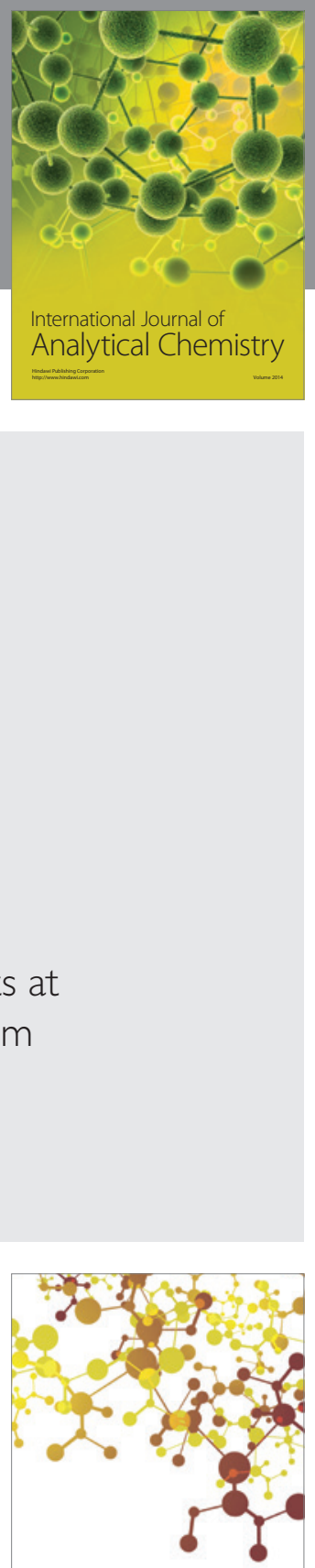

Journal of

Applied Chemistry
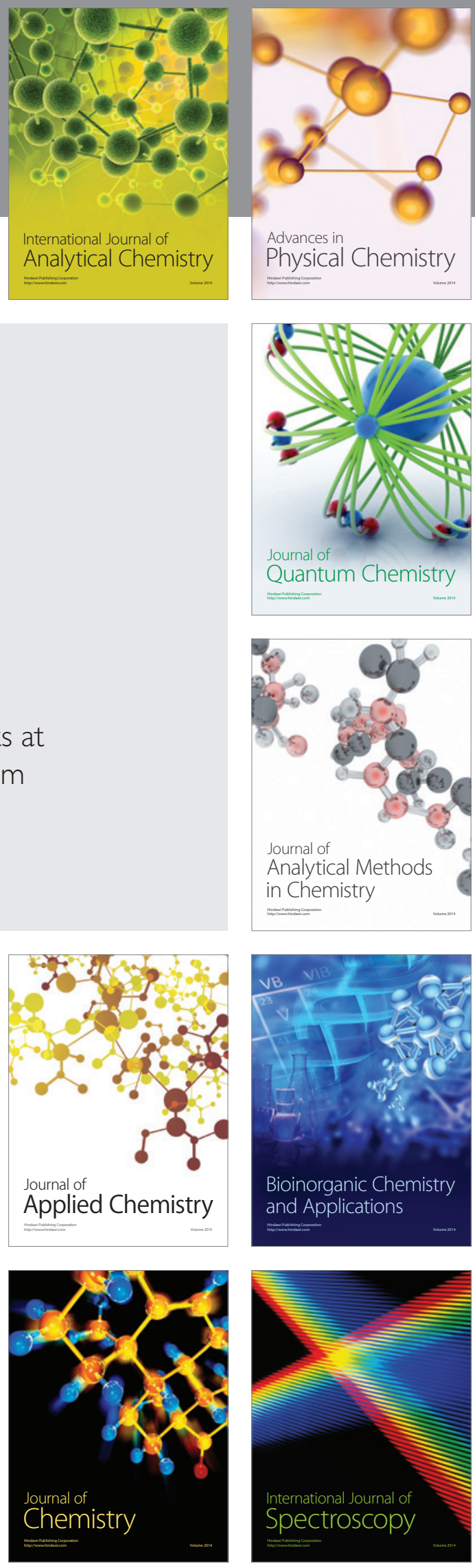